\title{
NEAMS Experimental Support for Code Validation, INL FY2009
}

G. Youinou

G. Palmiotti

M. Salvatores

C. Rabiti

September 2009

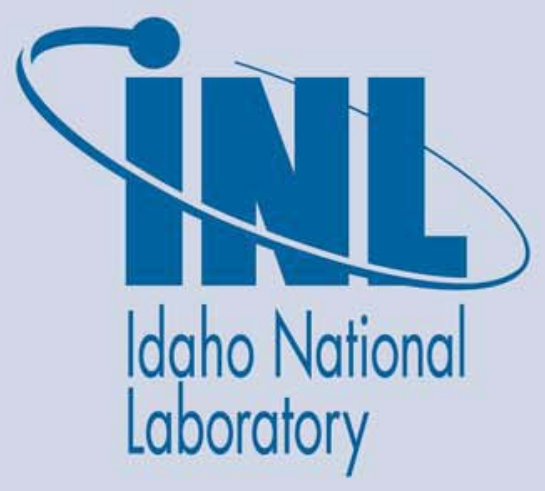

The INL is a U.S. Department of Energy National Laboratory operated by Battelle Energy Alliance 
INL/EXT-10-17740

AFCI-MDSM-PMO-MI-DV-2009-000207

\title{
NEAMS Experimental Support for Code Validation, INL FY2009
}

\author{
G. Youinou \\ G. Palmiotti \\ M. Salvatores \\ C. Rabiti
}

September 2009

\section{Idaho National Laboratory Advanced Fuel Cycle Initiative Idaho Falls, Idaho 83415}

http://www.inl.gov

Prepared for the

U.S. Department of Energy

Office of Nuclear Energy

Under DOE Idaho Operations Office

Contract DE-AC07-05ID14517 


\section{NEAMS Experimental Support for Code Validation, INL FY2009 \\ Advanced Fuel Cycle Initiative}

Prepared for U.S. Department of Energy NEAMS Campaign G. Youinou, G. Palmiotti, M. Salvatores, C. Rabiti Idaho National Laboratory September 2009 AFCI-MDSM-PMO-MI-DV-2009-000207 INL/EXT-10-17740 


\section{DISCLAIMER}

This information was prepared as an account of work sponsored by an agency of the U.S. Government. Neither the U.S. Government nor any agency thereof, nor any of their employees, makes any warranty, expressed or implied, or assumes any legal liability or responsibility for the accuracy, completeness, or usefulness, of any information, apparatus, product, or process disclosed, or represents that its use would not infringe privately owned rights. References herein to any specific commercial product, process, or service by trade name, trade mark, manufacturer, or otherwise, does not necessarily constitute or imply its endorsement, recommendation, or favoring by the U.S. Government or any agency thereof. The views and opinions of authors expressed herein do not necessarily state or reflect those of the U.S. Government or any agency thereof. 
$08 / 05 / 2009$

Rev. 2

AFCI-TIO-PMO-QA-FM-2009-00052

Name/Title of Deliverable/Milestone

Work Package Title and Number

Work Package WBS Number

Responsible Work Package Manager

\section{AFCI Document Cover Sheet}

Page 1 of 1

NEAMS Experimental Support for Code Validation, INL FY2009

Verification, Validation \& Uncertainty Quantification - INL \#IN0915090701

1.5.09.07

Giuseppe Palmiotti $r$, ind

(Name/Signature)

Date Submitted 9/19/2009

Quality Rigor Level for

Deliverable/Milestone

$\bigotimes$ Rigor Level $3 \square$ Rigor Level $2 \square$ Nuclear Data

This deliverable was prepared in accordance with Idaho National Laboratory

(Participant's (National Laboratory or
Subcontractor) Name)

QA program which meets the requirements of

$\bigotimes$ DOE Order 414.1 $\square$ Nuclear Data Requirements

This Deliverable was subjected to:

$\bigotimes$ Independent Technical Review

Independent Technical Review (ITR)

\section{Review Documentation}

Provided

Signed ITR Report or,

Peer Review (PR)

Review Documentation Provided

Signed PR Report or,

Signed ITR Concurrence

Sheet or,

\section{Signature of ITR}

Reviewer(s) below Sheet or,
Peer Review

\section{Nuclear Data Validation (NDV)}

Review Documentation Provid

Signed Validation Documentation or,

Signed Validation Concurrence or,

Signature of Validation Reviewer(s) below,

Name and Signature of Peer Reviewers(s)/Independent Technical Reviewer(s) (NOTE:

Electronic signatures or other proof of approval (e-mails, other electronic verification) may be provided in lieu of signatures on this form)

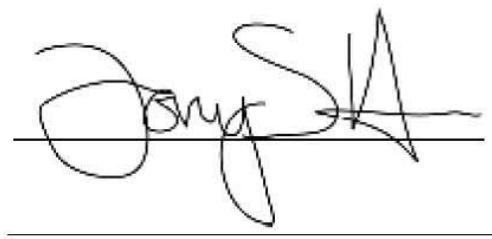


08/05/2009

Rev. 2

AFCI-TIO-PMO-QA-FM-2009-00052

Temitope Taiwo
AFCI Document Cover Sheet

Page 2 of 1 


\section{SUMMARY}

The goal is for all modeling and simulation tools to be demonstrated accurate and reliable through a formal Verification and Validation (V\&V) process, especially where such tools are to be used to establish safety margins and support regulatory compliance, or to design a system in a manner that reduces the role of expensive mockups and prototypes.

Whereas the Verification part of the process does not rely on experiment, the Validation part, on the contrary, necessitates as many relevant and precise experimental data as possible to make sure the models reproduce reality as closely as possible.

Hence, this report presents a limited selection of experimental data that could be used to validate the codes devoted mainly to Fast Neutron Reactor calculations in the US. Emphasis has been put on existing data for thermal-hydraulics, fuel and reactor physics. The principles of a new "smart" experiment that could be used to improve our knowledge of neutron cross-sections are presented as well. In short, it consists in irradiating a few milligrams of actinides and analyzing the results with Accelerator Mass Spectroscopy to infer the neutron cross-sections.

Finally, the wealth of experimental data relevant to Fast Neutron Reactors in the US should not be taken for granted and efforts should be put on saving these 30-40 years old data and on making sure they are validation-worthy, i.e. that the experimental conditions and uncertainties are well documented. 


\section{CONTENTS}

SUMMARY V

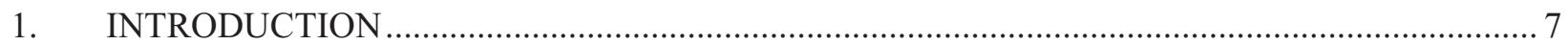

2. A Reliable Methodology For Code Validation Using Integral Experiments.................................... 8

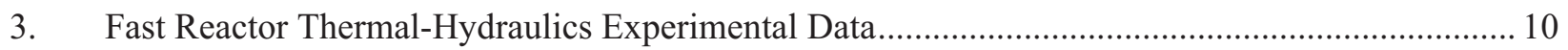

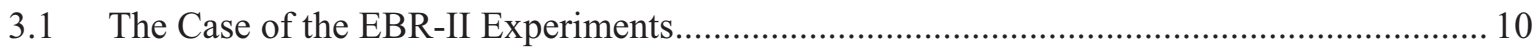

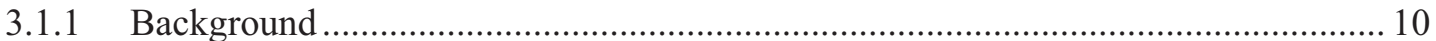

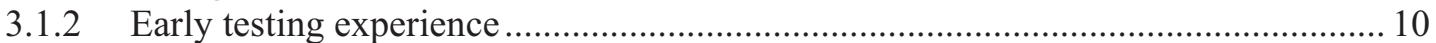

3.1.3 The Shutdown Heat Removal Test (SHRT) program ............................................ 12

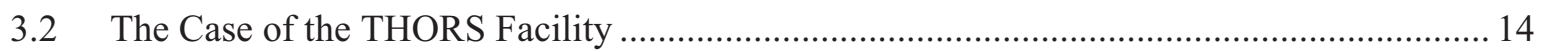

4. Past Argonne Thermal-Hydraulic Studies on Individual Components and In-Vessel System

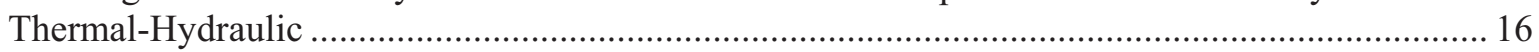

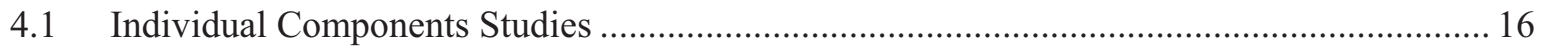

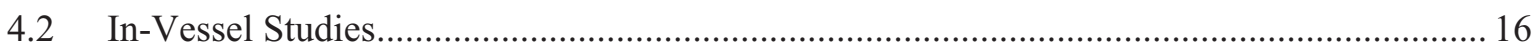

5. Fast Reactor Fuel Experimental Data. A US Perspective.......................................................... 18

6. Criticality Experimental Data. The Case of the International Handbook of Evaluated Criticality Safety Benchmark Experiments .......................................................................... 21

7. Reactor Physics Experimental Data. The Case of the International Handbook of Evaluated

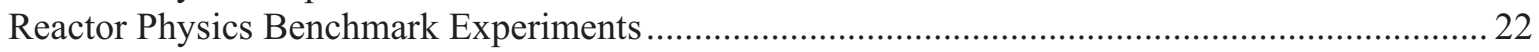

8. The MANTRA Experiment: A New Reactor Physics Experiment in the US ............................... 24

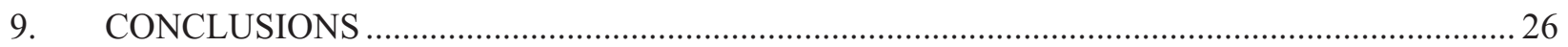




\section{NEAMS CAMPAIGN NEAMS EXPERIMENTAL SUPPORT FOR CODE VALIDATION, INL FY2009}

\section{INTRODUCTION}

The goal is for all modeling and simulation tools to be demonstrated accurate and reliable through a formal Verification and Validation (V\&V) process, especially where such tools are to be used to establish safety margins and support regulatory compliance, or to design a system in a manner that reduces the role of expensive mockups and prototypes. Whereas the Verification part of the process does not rely on experiment, the Validation part, on the contrary, necessitates as many relevant and precise experimental data as possible to make sure the models reproduce reality as closely as possible. With this regard the INL Experimental Roadmap for Thermal Hydraulic Code Validation (INL/EXT-07-13248 from Glenn E. McCreery, Hugh M. McIlroy) makes an important remark:

"A review of the technical literature reveals a huge number of reports that document the results of various experimental studies. However, few of these reports describe in sufficient detail the critical elements of the experiment such as initial or boundary conditions or uncertainty (error) estimates and analysis that are necessary for consideration as a source of data for code validation. Additionally, the literature indicates that there is a need to identify specific experimental principles that must be followed in order to ensure that experimental data meet the standard required of a "benchmark" database."

Indeed, since most of the time, the team in charge of carrying out the experiment and the team in charge of validating computer models are not the same and have different concerns, the writing of the experimental report should be an iterative process that ends only when both parties are satisfied with the results. It is the only way to ensure that the experimental report leaves nothing to the imagination and thus can be used in the future.

This report presents a limited collection of experimental data that could be used to validate the codes mainly devoted to Fast Neutron Reactor calculations in the US. Chapter 2 presents a methodology that allows a consistent use of integral experiments for code validation. Chapter 3 focuses on in-core thermalhydraulics with the cases of EBR-II and THORS. Chapter 4 deals with individual components and invessel system thermal-hydraulics. Chapter 5 presents the experimental data relative to fast reactor fuel in the US. Chapters $6 \& 7$ are related to neutron physics data (criticality and reactor physics) whereas Chapter 8 presents the principles of a new "smart" experiment that could be used to improve our knowledge of neutron cross-sections.. Finally, Chapter 9 concludes this report. 


\section{A Reliable Methodology For Code Validation Using Integral Experiments}

Source: "A global approach to the physics validation of simulation codes for future nuclear systems", G. Palmiotti et al., Annals of Nuclear Energy 36 (2009)

The methodology presented in this chapter has been used essentially in neutronics to adjust neutron crosssections so that the results of the calculations fit more closely the results of the measurements. However, since it relies, in essence, only on sensitivity coefficients and covariance matrices, it is very general and could in principle be applied to other fields as long as the physics does not exhibit too strong nonlinearities. However, even in the case of large nonlinearity the same approach can be used in an iterative way, where successive linear applications are used until convergence.

The methodology uses covariance data and selected integral experiments together with classical statistical adjustment techniques. These techniques provide adjusted nuclear data for a wide range of applications, together with new, improved covariance data and bias factors (with reduced uncertainties) for the required design parameters, in order to meet target accuracies.

In fact, if we define $B_{P}$ the "a priori" nuclear data covariance matrix, $S_{R}$ the sensitivity matrix of the performance parameters $\mathrm{R}(\mathrm{R}=1, \ldots, \mathrm{RTOT})$ to the $\mathrm{J}$ nuclear data, the "a priori" covariance matrix of the performance parameters is given by:

$$
B_{R}=S_{R}^{T} B_{p} S_{R}
$$

It can be shown that, using a set of $I$ integral experiments $E$, characterized by a sensitivity matrix $S_{E}$, besides a set of statistically adjusted cross-section data, a new ("a posteriori") covariance matrix $\widetilde{B}_{P}$ can be obtained:

$$
\tilde{B}_{p}=B_{p}-B_{p} S_{E}\left(S_{E}^{T} B_{p} S_{E}+B_{E}\right)^{-1} S_{E}^{T} B_{p}
$$

where $B_{E}$ is the integral experiment uncertainty matrix $\left(b_{i i}\right.$ are the experimental uncertainties of each experiment $i$ ) and $S_{E}$ is the sensitivity matrix of the $I$ experiments to the $J$ nuclear parameters (crosssections by energy group, isotope, and reaction type).

The selected integral experiments should meet a series of requirements: (a) low and well documented experimental uncertainties; (b) enabling to separate effects; and (c) allowing validating global effects. As for the point (b) above, irradiation experiments (as an example for the specific case of neutronics), in particular of separate isotope samples, allow to have very significant information on capture data, while fission rate experiments in well characterized spectra provide high accuracy information on fission data. As for the point (c), the global validation should be envisaged using as far as possible "representative" experiments, according to the definition given below, while specific effects should be singled out with appropriate experiments.

We can consider an integral experiment conceived in order to reduce the uncertainty $B_{R}$. If $S_{E}$ is the sensitivity matrix associated with this experiment we call "representativity factor" the following expression:

$$
r_{R E}=\frac{\left(S_{R}^{T} B_{p} S_{E}\right)}{\left[\left(S_{R}^{T} B_{p} S_{R}\right)\left(S_{E}^{T} B_{p} S_{E}\right)\right]^{1 / 2}}
$$

The uncertainty on the reference parameter $\mathrm{R}$ is reduced by: 


$$
\tilde{B}_{R}=B_{R}\left(1-r_{R E}^{2}\right)
$$

If more than one experiment is available, the previous equation can be generalized. In the case of two experiments, characterized by sensitivity matrices $S_{E 1}$ and $S_{E 2}$ the following expression can be derived:

$$
\tilde{B}_{R}=S_{R}^{T} \tilde{B}_{p} S_{R}=B_{R}\left[1-\frac{1}{1-r_{12}^{2}}\left(r_{R 1}-r_{R 2}\right)^{2}-\frac{2}{1+r_{12}} r_{R 1} r_{R 2}\right]
$$

Where $\widetilde{B}_{P}$ is the new covariance matrix and

$$
\begin{aligned}
& r_{12}=\frac{\left(S_{E 1}^{T} B_{p} S_{E 2}\right)}{\left[\left(S_{E 1}^{T} B_{p} S_{E 1}\right)\left(S_{E 2}^{T} B_{p} S_{E 2}\right)\right]^{1 / 2}} \\
& r_{R 1}=\frac{\left(S_{R}^{T} B_{p} S_{E 1}\right)}{\left[\left(S_{R}^{T} B_{p} S_{R}\right)\left(S_{E 1}^{T} B_{p} S_{E 1}\right)\right]^{1 / 2}} \\
& r_{R 2}=\frac{\left(S_{R}^{T} B_{p} S_{E 2}\right)}{\left[\left(S_{R}^{T} B_{p} S_{R}\right)\left(S_{E 2}^{T} B_{p} S_{E 2}\right)\right]^{1 / 2}}
\end{aligned}
$$




\section{Fast Reactor Thermal-Hydraulics Experimental Data}

\subsection{The Case of the EBR-II Experiments}

Source: Nuclear Engineering and Design 101 (1987), Special Issue on EBR-II.

Concerning the EBR-II experimental results the INL Experimental Roadmap for Thermal Hydraulic Code Validation (INL/EXT-07-13248 from Glenn E. McCreery, Hugh M. Mcllroy) states that "Much of the original experiment data and design documents are no longer available. Effort should be made to properly catalog and document available EBRII documents before they are lost."

\subsubsection{Background}

The thermal-hydraulic testing program at EBR-II, initially conducted to support the continued safe and reliable operation of EBR-II, has evolved into an experimental and supporting analytical program contributing to the design and performance assessment of advanced liquid-metal-reactors, with special emphasis on inherent safety. These efforts, which essentially started in 1974, have been primarily directed towards understanding the detailed response of EBR-II to a wide variety of upset conditions and utilizing this knowledge to validate general purpose thermal-hydraulic-neutronic computer codes for application to new plant designs. Initial emphasis was placed upon reactor and primary heat transport system phenomena, and later, the focus of the work has been on whole-plant dynamic behavior.

The success of this program has been immeasurably aided by the availability of fully-instrumented and calibrated in-core fueled and non-fueled assemblies, XX07, XX08, XX09 and XX10. These assemblies give direct, real time measurements of in-core sodium temperatures. Their extensive temperature and flowrate measuring capabilities, have permitted the generation and documentation of comprehensive data sets that have been used to validate codes modeling single and multiple assemblies, and whole core behavior. Plant instrumentation has been upgraded so that flowrates and temperatures in the primary, secondary, and steam systems can be measured. Additional control systems have been added to facilitate the conduct of whole-plant dynamic testing.

\subsubsection{Early testing experience}

The experimental program at EBR-II has of necessity been evolutionary in nature, due to the need of conducting the mildest tests first in order to avoid any potential risk to the on-going operation of the plant, as well as to the learning process which generated new tests specifically designed to answer questions or resolve uncertainties arising from completed tests and analyses. Accordingly, the emphasis of the early tests was on steady-state natural circulation under conditions of either decay or fission power. These tests evaluated the effects of the fission or decay power level and the secondary flowrate upon the natural convective core flowrate and temperature rise. The post-test analyses not only permitted the EBR-II system simulation code NATDEMO to be validated for low flowrate conditions, but perhaps more importantly, quantified for the first time the strong inter-assembly flow redistribution that occurs during natural circulation.

This phenomenon, which was not modeled in the then available core thermal-hydraulic codes, resulted in a substantial decrease in the cross-core (as well as intra-assembly) temperature peaking factors used in natural circulation safety analyses. The only transient test conducted with XX07 installed, which was a loss of auxiliary pump forced flow at hot-standby conditions, demonstrated that the primary coolant flowrate could decrease to a very low value after the cessation of forced flow and prior to the development of buoyancy-driven flow. This observation led to the possibility of total flow reversal in 
cooler regions of the core (especially in the radial blanket) during a transition to natural circulation for certain types of loss of forced flow transients.

Figure 1. Schematic of the EBR-II plant

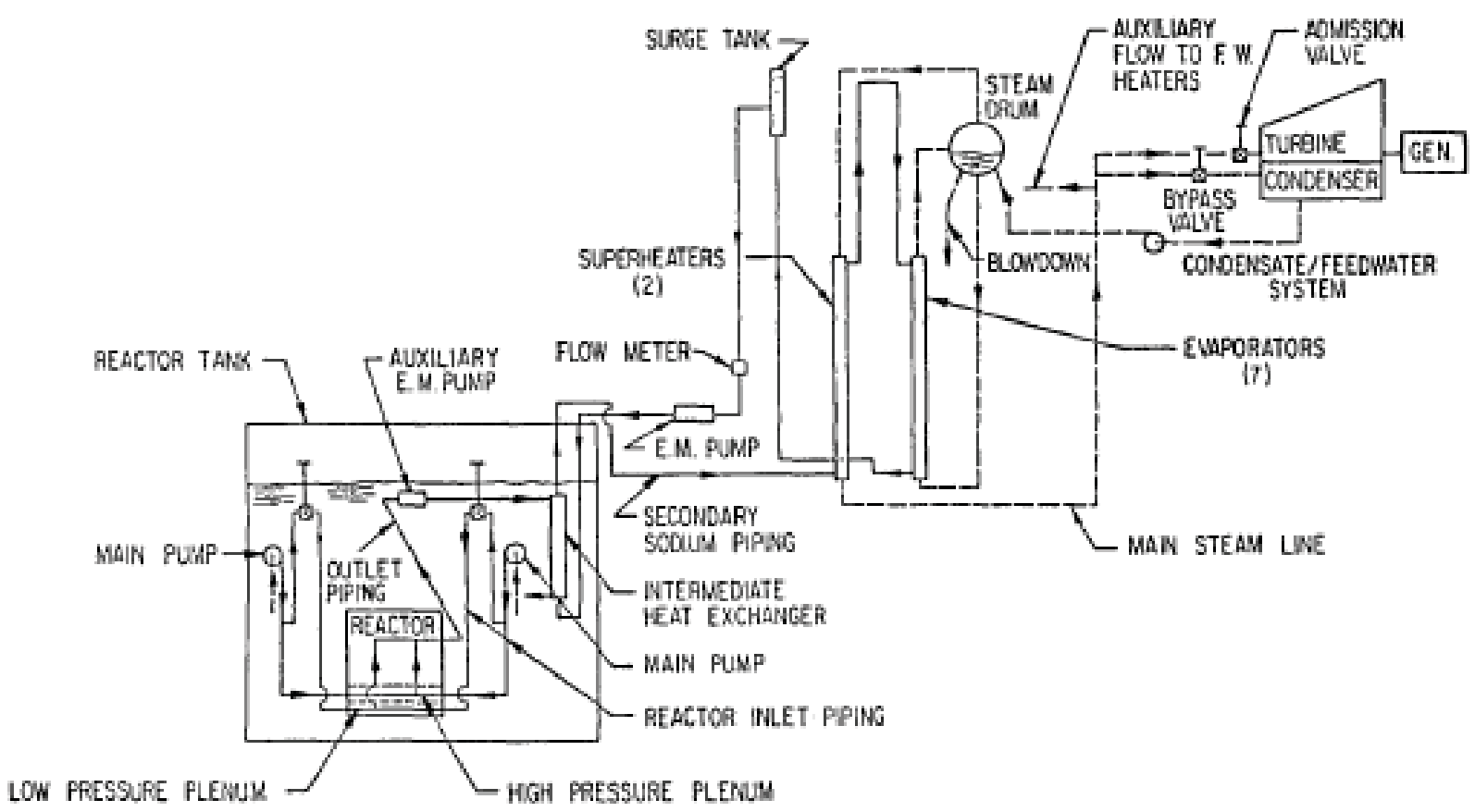

Accordingly, following the end of the useful life of XX07, the program was continued with a new instrumented assembly XX08, and emphasis was placed upon the dynamics of the transition from forced to natural convective flow from a wide variety of initial operating conditions and sequencing of scram and primary and secondary pump trip times. Loss-of-forced-flow transients were conducted from full primary flow at hot standby conditions, from auxiliary pump flow at decay power levels, and from various reduced levels of fission power and primary pump flow. The analysis of these test results clearly demonstrated that transients initiated from conditions in which relatively normal temperature gradients existed in the system (i.e., power-to-flow ratios close to unity) lead to a smooth and benign transition to natural circulation.

However, when the transient imposed resulted in a significant degradation of the thermal head in the primary circuit prior to the loss of forced flow, a substantial and temporarily sustained total reversal of flow occurred in the lower power regions of EBR-II (i.e., the radial blanket and reflector regions). An additional result of the post-test analyses revealed that the validation of the NATDEMO code accomplished at steady-state natural circulation conditions was valid for the full range of transients studied. In addition to providing verification of the EBR-II NATDEMO code, the data generated from these tests were used to validate codes used to support the FFTF natural circulation acceptance testing and the CRBRP natural circulation evaluations. As examples of these efforts, the IHX and secondary loop hot leg piping models in the CRBRP simulation code DEMO were verified from transient data measured in the corresponding parts of the EBR-II plant.

Data from the instrumented assemblies XX07 and XX08 during various natural circulation transients were used to validate the whole core/assembly code COBRA-WC and the hot channel code FORE-2M. The three-dimensional thermal-hydraulics code, COMMIX-1A, was similarly validated by modeling the XX08 test in which total flow reversal occurred in the radial blanket/reflector region during a natural circulation transient. Verification studies were also conducted with SASSYS, SSC, MINET, and CORA, 
an FFTF code. The success of these efforts, the improved understanding of the types of new data required for code validation, and the increased emphasis of DOE and reactor designers on inherent safety, lead to the initiation of the XX09/XX10 SHRT program. This program, which was intended to extend previous testing to the maximum capability of EBR-II as well as to provide detailed data on inter-assembly flow redistribution and inherent reactor shutdown by reactivity feedbacks, is discussed in the following section.

\subsubsection{The Shutdown Heat Removal Test (SHRT) program}

The SHRT Program was developed jointly by thermal-hydraulics (T-H) specialists from EBR-II and Department of Energy contractor organizations, largely in support of the design of LMR plants in the U.S. The objectives of this program were to:

1. demonstrate passive removal of decay heat following reactor shutdown by natural circulation of primary sodium coolant;

2. demonstrate passive reactor shutdown following a loss of forced circulation (LOFWS);

3. demonstrate passive reactor shutdown following a loss of balance-of-plant (BOP) heat sink (LOHSWS) and

4. provide test data for validating computer codes used in the design, licensing, and operation of LMRs.

Each of the total of 58 tests in the SHRT Program was one of the five following types:

A. $\mathrm{LOF} / \mathrm{scram}$ to natural circulation

B. Scram with delayed LOF to natural circulation

C. Reactivity feedback characterization

D. LOFWS

E. Balance of plant transients

1. dynamic frequency response test

2. LOHSWS

3. steam drum pressure reduction

The LOFWS and LOHSWS tests from 100\% initial power were both rerun on April 3, 1986 as an inherent safety demonstration. Most important to this paper were the higher power LOFWS tests, and the LOHSWS tests. Brief overviews of the SHRT tests are provided in the following section.

\subsubsection{LOF/scram to natural circulation}

The essential parameters that were studied in this sequence are the initial power and primary flowrate and the trip/non-trip of the secondary pump. The first test, which duplicates one that was conducted earlier with XX08, was initiated from $36 \%$ of full power and $40 \%$ of full flow by tripping the primary pumps. In addition, several different combinations of primary pump rundown times and delays in the secondary pump trip were studied. In all cases, the final state of the plant is natural circulation in both the primary and secondary systems. The subsequent test initial conditions were power and primary flow levels of $75 \% / 100 \%, 75 \% / 75 \%$, and $100 \% / 100 \%$, respectively. For each of these test conditions (with the auxiliary pump turned off), the secondary flow was in the first case slowly reduced to about $20 \%$ or in the second case permitted to rapidly coastdown to natural circulation. Thus, the final test in this group directly simulated a total loss of pumping power (normal and emergency) to the plant while operating at full power and flow.

\subsubsection{Scram with delayed LOF to natural circulation}

Most of these tests were initiated from normal full power and flow where the first step was to scram the reactor while maintaining either full primary flow or auxiliary pump (-5\%) flow. After a prescribed delay 
during which time the primary system approached isothermal conditions, the primary pumps (or the auxiliary pump) were tripped and the flow coasted down to natural circulation. The effect of the level and rate of coastdown of secondary flow was also studied. During these transients, the coolant flow in the radial blanket-reflector region either temporarily stagnated or reversed due to the adverse thermal conditions delaying the transition to upward natural convection.

\subsubsection{Reactivity feedback characterization}

These tests were designed to provide measurements of the dynamic plant response to flow and inlet temperature perturbations in order to permit validation of the reactivity feedback models in NATDEMO. A series of thermal-hydraulic disturbances was imposed upon the core, maintaining fixed (or precisely changed) control rod positions, in order to measure the resulting power changes and thereby in compute the effective reactivity feedbacks through an inverse kinetics calculation. The first type of disturbance was a change in primary flowrate, holding the reactor inlet temperature and control rod positions fixed. This causes the reactor AT to change initially, affecting the reactivity balance, which drives a power change. Initial power levels of $25 \%, 50 \%$, and $70 \%$ were used. The second type of disturbance was a change (either decrease or increase) in the reactor inlet temperature (caused by changes in the secondary flowrate), while the primary flowrate and control rod positions were fixed. Initial power levels of $25 \%$, $50 \%$, and $70 \%$ were used. A variation of the two types of disturbances employed was a flowrate or inlet temperature disturbance followed by a change in control rod position sufficient to return the power to its initial value.

\subsubsection{Loss of flow without reactor scram}

This sequence of tests involved coolant pump trips without permitting a reactor scram. The initial tests used different combinations of rate of primary pump coastdown, trip or non-trip of the secondary pump, and operation of the auxiliary pump on emergency power, battery power, or not operated at all. These tests were initiated from various power and flowrates, culminating in 100\% power and flow. The mildest transients, in terms of maximum core temperatures, were conducted first, with the severity gradually increased. Included among these tests were an unprotected LOF to natural circulation from full power as well as an unprotected station blackout (loss of normal and emergency a-c electric power without scram).

\subsubsection{Balance of plant transients}

Dynamic frequency response tests. There tests were designed to generate data over a wide disturbance frequency range that can be used to validate whole plant dynamic simulation models. There were types of cyclic tests in which a relatively small periodic disturbance was added to either control-rod-inserted reactivity or secondary loop electromagnetic pump voltage. This periodic disturbance consisted of a fundamental frequency and a number of harmonics. The propagation and attenuation of these frequencies in the form of power, temperature, flow, and pressure disturbances was measured throughout the plant. Spectral analysis was applied to both the measured output and the simulation results, providing transfer functions for each. A comparison of the two sets of results (measured vs. calculated) is a direct measurement of the efficacy of the calculational models. In the first group, the automatic control rod drive system (ACRDS) was used to produce a periodic disturbance in reactivity. All of the tests were performed at a relative power-to-flow ratio near unity, although tests were also done both near full power and half power. Although several frequencies could have been contained in the periodic input wave of each test, two tests were required at each power level to adequately cover the frequency range of interest. The second group of tests was analogous to the first and again required two power levels and two tests at each power level. However, instead of using the ACRDS to disturb reactivity, the appropriate periodic disturbances were added to the secondary EM pump voltage. 
Loss of heat sink without scram. This test has as its objective the demonstration that the reactor will passively shut itself down following a total loss of heat sink, including the emergency decay heat removal system. Experimentally, this was accomplished by essentially stopping the secondary flow (including natural circulation) without permitting the reactor to scram, and maintaining full primary flow. These particular conditions were chosen to umbrella all possible loss of normal heat sink transients. In this case, the loss of heat removal from the primary system caused the reactor inlet temperature to increase and thus the reactor power to decrease due to the negative reactivity feedbacks. Although the inlet temperature rose substantially, the resulting power reduction was sufficiently large and rapid to cause a reduction in the outlet temperature so that the core $\Delta \mathrm{T}$ actually decreased to only several degrees and the entire primary system approached an isothermal condition. The asymptotic temperature reached (with the reactor just critical at near zero power) is sometimes referred to as the reactor "quenching temperature".

Steam drum pressure reduction. Two tests were run which involved a rapid opening of the steam bypass valve to the condenser and a rapid steam depressurization. The primary and secondary flowrates were held constant. Reactor power and temperatures were allowed to freely respond. The decrease in the steam drum pressure and in its water saturation temperature reduced the secondary sodium temperature exiting the evaporators. This reduced secondary sodium temperature overcooled the primary sodium in the IHX, thus reducing the reactor inlet temperature. Due to the negative reactivity feedbacks, the reactor power increased to meet the increased steam power demand. The reactor and secondary loop $\Delta$ Ts were fixed by the reactor and secondary flowrates and the power demand.

\subsection{The Case of the THORS Facility}

Source: "Forced-to-natural convection transition tests in parallel simulated liquid metal reactor fuel assemblies", International topical meeting on fast reactor safety, Snowbird, UT (USA), 12-16 Aug 1990

The Thermal-Hydraulic Out of Reactor Safety (THORS) Program at Oak Ridge National Laboratory (ORNL) had as its objective the testing of simulated, electrically heated liquid metal reactor (LMR) fuel assemblies in an engineering scale, sodium loop. Between 1971 and 1985, the THORS Program operated 11 simulated fuel bundles in conditions covering a wide range of normal and off-normal conditions. The last test series in the Program, THORS-SHRS Assembly 1, employed two parallel, 19 pin, full-length, simulated fuel assemblies of a design consistent with the large LMR (Large Scale Prototype Breeder LSPB) under development at that time. These bundles were installed in the THORS Facility, allowing single- and parallel-bundle testing in thermal-hydraulic conditions up to and including sodium boiling and dryout. As the name SHRS (Shutdown Heat Removal System) implies, a major objective of the program was testing under conditions expected during low-power reactor operation, including low-flow forced convection, natural convection, and forced-to-natural convection transition at various powers.

The THORS-SHRS Assembly 1 experimental program was divided up into four phases. Phase 1 included preliminary and shakedown tests, including the collection of baseline steady-state thermal-hydraulic data. Phase 2 comprised natural convection testing. Forced convection testing was conducted in Phase 3 . The final phase of testing included forced-to natural convection transition tests.

The two simulated fuel assemblies were of identical design, each containing 19 fuel pin simulators (FPSs) based on an LSPB driver assembly. The FPSs were $6.99 \mathrm{~mm}$ in diameter, spaced by $1.22 \mathrm{~mm}$ diameter wire wraps with a helical pitch of $305 \mathrm{~mm}$. The edge gaps between the outermost row of FPSs and the hexcan were half-size $(0.61 \mathrm{~mm})$ to reduce the flow-to-power ratio in these subchannels, thus flattening the bundle radial temperature profile. The axial power shape was a chopped cosine, with a peak-to-mean ratio of 1.28. The heated length was $1016 \mathrm{~mm}$. Each FPS included simulated lower and upper axial blankets and a simulated fission gas plenum (SFGP). The maximum FPS power was about $28 \mathrm{~kW}$. The THORS Facility was extensively instrumented for this test program. 
Figure 2. Schematic of the THORS-SHRS facility

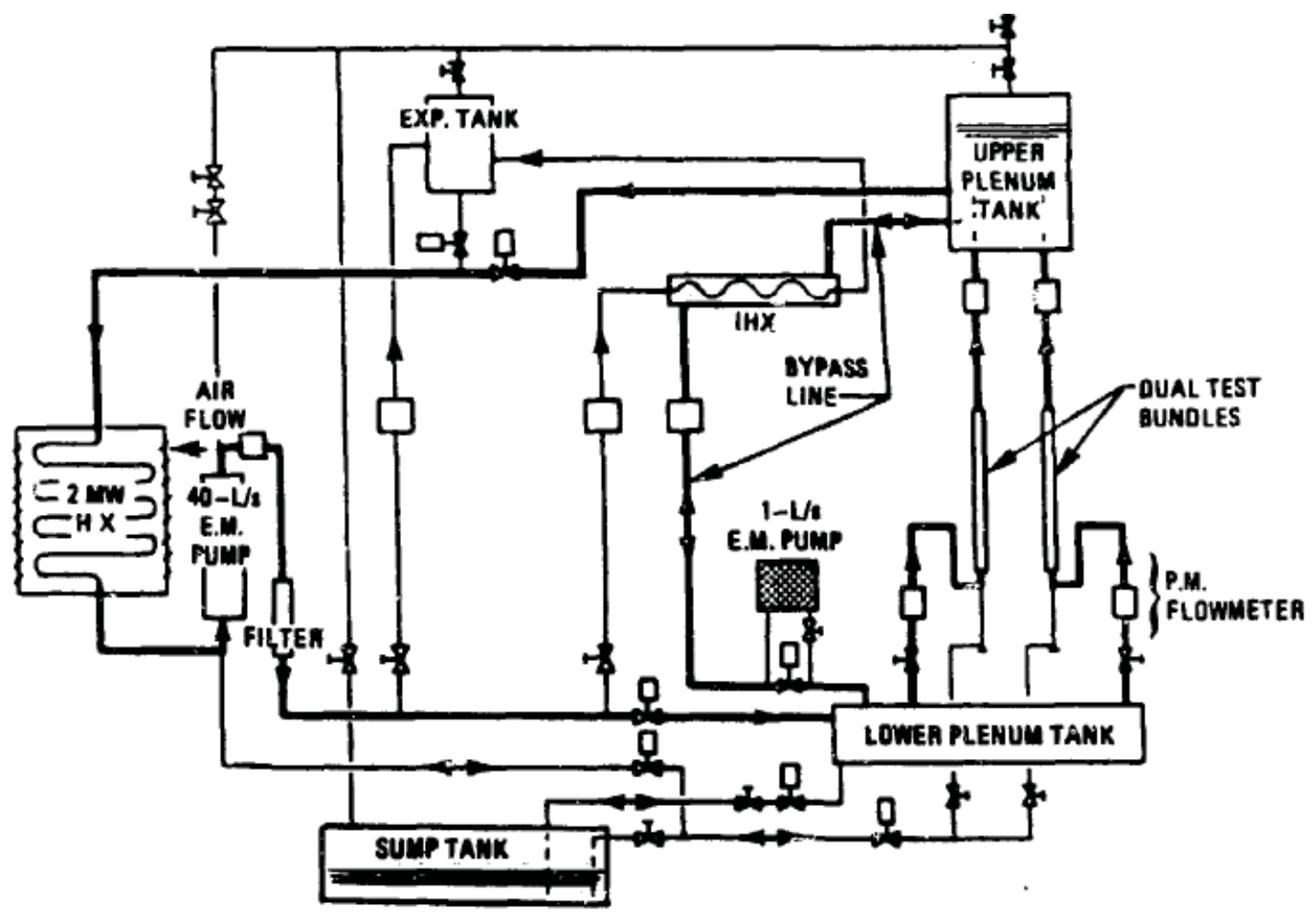

Since temperature distributions throughout the loop were of considerable importance during natural convection testing, thermocouples were placed throughout the "primary" side of the system. The bundles were also heavily instrumented, with 118 thermocouples placed in each bundle: three on the inner sheath of each FPS and 61 in the wire-wrap spacers. The upper and lower plena also contained substantial thermocouple coverage, in order to detect re-circulating flows in these components. System pressures were monitored using NaK-filled transducers, and flows were measured using permanent-magnet flowmeters. The test section inlet flowmeters were removable, allowing sensitive, low-range flowmeters to be installed during natural convection tests. Data acquisition was accomplished using a sophisticated computer controlled data acquisition system, capable of monitoring up to 10,000 points per second from up to 500 instruments. 


\section{Past Argonne Thermal-Hydraulic Studies on Individual Components and In-Vessel System Thermal-Hydraulic}

Source: "Argonne Liquid-Metal Advanced Burner Reactor: Components and In-Vessel System ThermalHydraulic Research and Testing Experience Pathway Forward", ANL/NE-07/21, 2007

\subsection{Individual Components Studies}

Beginning in the early 1970s, Argonne conducted studies on thermal buoyancy effects in individual reactor components in order to understand how these phenomena can influence component performance. In general, thermal-buoyancy-induced flow and associated thermal phenomena become important during the transition to and during natural circulation. The following is a list of individual reactor components, associated phenomena, and component issues studied by Argonne:

a) Pipe flow stratification that produces pipe stress and thermal stripping and influences energy transport between components with the potential for causing large departures from 1-D or inadequate 3-D CFD models of pipe flow

b) Stratification at pipe flow/plenum interfaces causing pipe flow recirculation zones and promoting large nozzle stresses

c) Steam-generator and heat-exchanger flow channeling and instabilities that cause tube-bundle, tubesheet, and shell thermal stress

d) Large-scale shear flow that produces periodic eddies which strongly influence thermal-plume behavior and plenum mixing, and can cause structural fatigue (thermal stripping) induced by thermal cycling

e) Thermal-buoyancy-force-induced laminarization of stratified shear layers, a mechanism that mitigates thermal stripping and reduces plenum mixing or, if the layers are unstable, can induce thermal stripping

f) Thermal-buoyancy-force suppression or enhancement of heat transfer under low flow, which can influence the overall heat transfer through a heat exchanger

g) Buoyancy-induced recirculation zones in baffled tube bundles and other components, which reduce heat transfer and produce radial temperature variation and "cold" spots, potentially causing large-scale detrimental structural stress.

\subsection{In-Vessel Studies}

Argonne in the 1970s and 1980s conducted studies based on water experiments addressing the flow and thermal behavior in LMR core outlets and plenums. The early studies were in support of Clinch River Breeder Reactor (CRBR) and used simplified models of the core outlet and upper plenums to explore thermal plume behavior above the core and stratification in the plenum. These studies also addressed the potential for thermal stripping at the core outlets and on the upper internals structures due to outlet temperature non-uniformities in the core sub-region. Starting in the early 1980s, Argonne conducted complete in-vessel thermal-hydraulic studies of the proposed GE/PRISM and RI/CE/SAFR reactor concepts.

These studies focused on the complex thermal hydraulic interactions that occur between the in-vessel components during the low-flow thermal transients associated with transition to natural circulation and decay heat removal. These interactions are produced by very strong thermal-buoyancy fluid forces, which not only effect individual-component thermal and structural behavior but also strongly influence global- 
reactor decay heat removal and general-reactor cooling under low-flow operation. The thermal buoyancy forces cause the momentum and energy equations to become strongly coupled and the flow and thermal fields to be highly non 1-D. This causes gross errors in component and system design results that are based on 1-D flow-distribution modeling, in which the thermal effects are transported solely as a passive scalar with the only dependence on temperature being through the fluid properties. Gross design errors can also be introduced if the design is based on experimental data correlations or performance verification using isothermal flow testing.. 


\section{Fast Reactor Fuel Experimental Data. A US Perspective.}

Source: Journal of Nuclear Material 371 (2007), "Fuels for sodium-cooled fast reactors: US perspective"

The US fast reactor fuel experience reflects the efforts of a large number of organizations from government, national laboratories, industry, and academia, all of whom have worked from 1947 until now (with a brief hiatus in the 1990s) as part of the nation's broader effort to develop fast reactors with fuel recycle. A strong emphasis on preparing the technology for commercialization in the 1970s and 1980s led to extensive test programs in EBR-II, FFTF, and TREAT, which were performed alongside similar efforts in other nations and included international collaboration. The table below presents a comparative summary of the experience with metal, MOX, and MC fuels.

Summary of US fast reactor fuels experience base

\begin{tabular}{|c|c|c|c|}
\hline \multirow[t]{2}{*}{ US experience } & \multicolumn{3}{|l|}{ Fuel type, cladding, and burnup } \\
\hline & Metal & Mixed oxide $(\mathrm{U}, \mathrm{Pu}) \mathrm{O}_{2}$ & Mixed carbide $(\mathrm{U}, \mathrm{Pu}) \mathrm{C} /(\mathrm{U}, \mathrm{Pu})_{2} \mathrm{C}_{3}$ \\
\hline $\begin{array}{l}\text { Driver fuel } \\
\text { operation }\end{array}$ & $\begin{array}{l}\sim 90000 \mathrm{U}-\mathrm{Fs} \text { rods in } \\
304 \mathrm{LSS} \text { to } 1-3 \text { at. } \% \\
>30000 \mathrm{U}-\mathrm{Fs} \text { rods in } 316 \mathrm{SS} \\
\text { to } 8 \text { at. } \% \\
\sim 13000 \mathrm{U}-\mathrm{Zr} \text { in } 316 \mathrm{SS} \\
10 \text { at. } \%\end{array}$ & $\begin{array}{l}>48000 \text { MOX rods in } 316 \mathrm{SS} \\
\text { (Series I\&II) to } 80 \mathrm{GWd} / \\
\text { MTHM }\end{array}$ & None applicable \\
\hline $\begin{array}{l}\text { Through } \\
\text { qualification }\end{array}$ & $\begin{array}{l}\text { U-Zr in } 316 \mathrm{SS}, \mathrm{D} 9, \mathrm{HT} 9 . \\
10 \text { at. } \% \text { in EBR-II and FFTF }\end{array}$ & $\begin{array}{l}\text { MOX in HT } 9 \text { to } 15-20 \text { at. } \% \text { bu } \\
\text { (CDE) MOX in } 316 \mathrm{SS} \\
\text { (Series I\&II) to } 100 \mathrm{GWd} / \\
\text { MTHM }\end{array}$ & None applicable \\
\hline $\begin{array}{l}\text { Demonstrated } \\
\text { burnup } \\
\text { capability and } \\
\text { experiments }\end{array}$ & $\begin{array}{l}\text { U-Pu-Zr in D } 9 \text { and } \mathrm{HT} 9 \text { to } \\
10-20 \text { at. } \% \text { in EBR-II and } \\
\text { FFTF }\end{array}$ & $\begin{array}{l}4300 \mathrm{MOX} \text { rods in } 316 \mathrm{SS} \text { to } \\
100 \mathrm{GWd} / \mathrm{MTHM} \text { in FFTF; } \\
\text { fab var's; CL melt } \\
>3000 \mathrm{MOX} \text { rods in } 316 \mathrm{SS} \text { to } \\
5-17.5 \text { at. } \% \text { in EBR-II } 2377 \\
\text { MOX rods in D } 9 \text { to } 100-129 \\
\text { GWd/MTHM; peak rods to } \\
188 \\
\text { GWd/MTHM }\end{array}$ & $\begin{array}{l}18 \text { EBR-II assemblies with } 472 \text { rods in } 316 \mathrm{SS} \\
\text { cladding; } 10 \text { rods up to } 20 \text { at. } \% \text { w/o breach, five } \\
\text { of which experienced } 15 \% \text { TOP at } 12 \text { at.\%; } 13 \\
\text { He-bonded and } 3 \text { Na-bonded rods up to } \\
16 \text { at. } \% \text { w/o breach } \\
219 \text { rods in FFTF, including } 91 \text { in D } 9 \text { cladding, } \\
\text { and } 91 \text { with particulate and pellet fuel }\end{array}$ \\
\hline $\begin{array}{l}\text { Safety and } \\
\text { operability }\end{array}$ & $\begin{array}{l}6 \mathrm{RBCB} \text { tests } \mathrm{U}-\mathrm{Fs} \text { and } \mathrm{U}_{-} \\
\mathrm{Pu}-\mathrm{Zr} / \mathrm{U}-\mathrm{Zr} \\
6 \mathrm{TREAT} \text { tests } \mathrm{U}-\mathrm{Fs} \text { in } \\
316 \mathrm{SS} \text { (9rods) and } \mathrm{U}-\mathrm{Zr} / \mathrm{U}- \\
\mathrm{Pu}-\mathrm{Zr} \text { in D9/HT9 (6 rods) }\end{array}$ & $\begin{array}{l}18 \text { RBCB tests; } 30 \text { breached } \\
\text { rods four slow ramp tests } \\
9 \text { TREAT tests MOX in } 316 \mathrm{SS} \\
\text { (14 rods) and HT9 ( } 5 \text { rods) }\end{array}$ & $\begin{array}{l}10 \text { TREAT tests ( } 10 \text { rods); up to } 3-6 \text { times } \\
\text { transient overpower margins to breach } \\
\text { Loss-of-Na bond followed by irradiation to } \\
3 \text { at. } \% \\
\text { RBCB for } 100 \text { EFPD centerline melting test }\end{array}$ \\
\hline
\end{tabular}

These programs and the associated efforts in materials development and evaluation, fabrication process development, and fuel behavior modeling addressed key questions and ultimately demonstrated that two, and possibly three, fuel types will meet SFR safety and performance requirements. In particular, the metal and MOX fuel programs evolved from experiments designed to assess fuel response under varied conditions and fuel lifetime to larger programs for establishing reliability of fuel designs in specific applications and addressing safety issues raised by independent safety experts - i.e., issues associated with implementation rather than issues of feasibility.

The questions that arise today are those associated with meeting the economic and mission requirements of SFR deployment, and internationally those are motivating extensions of the fuel technology R\&D into new fuel compositions and designs to reduce fabrication costs, increase burnup, and enhance safety. The MOX fuel database is well established in the US due to the experience gained with experiments in EBR-II and FFTF and with the operation of FFTF with a driver fuel design that closely resembles the design that 
would be implemented in a full-scale, MOX-fueled SFR. This maturity is also prevalent worldwide, as the result of efforts in Japan, France, Russia and the UK. The quality and safety discipline implemented for FFTF operation and experimentation were relevant to industrial implementation, so the US should have high confidence in the reliability and performance of MOX fuel at fuel utilization beyond 200 $\mathrm{GWd} / \mathrm{MTHM}$ and fast neutron exposures up to $4 \cdot 10^{23} \mathrm{n} / \mathrm{cm}^{2}$. The authors believe, leaving aside the issues associated with beyond-design basis events and hypothetical core disruption events, a licensing case for an industrial-scale demonstration reactor could be prepared with the existing MOX fuel database. A set of suggested design parameters for use of MOX fuel, similar to those used as reference for the FFTF Core Demonstration Experiment is presented in the table below.

\begin{tabular}{|c|c|c|c|}
\hline Parameter & Mixed oxide $(\mathrm{MOX})^{\mathrm{a}}$ & $\mathrm{U}-\mathrm{Pu}-\mathrm{Zr}^{\mathrm{b}}$ & Mixed carbide $(\mathrm{MC})^{\mathrm{c}}$ \\
\hline Nominal composition & $(\mathrm{U}, \mathrm{Pu}) \mathrm{O}_{2}$ & $\mathrm{U}-20 \mathrm{Pu}-10 \mathrm{Zr}$ & $(\mathrm{U}, \mathrm{Pu}) \mathrm{C}$ \\
\hline $\mathrm{Pu} /(\mathrm{U}+\mathrm{Pu})$ range & $22-30 \%$ & $17-28 \%$ & $21-23 \%$ \\
\hline Oxygen-to-metal ratio & 1.95 & $\mathrm{n} / \mathrm{a}$ & \\
\hline Fuel theoretical density & $92 \%$ & $100 \%{ }^{\mathrm{d}}$ & $80-82 \%$ \\
\hline Fuel smeared density ( $\%$ TD) & $80-85 \%$ & $75 \%$ & $78-79 \%$ \\
\hline Plenum-to-fuel volume ratio & 1.0 & 1.4 & 1.0 \\
\hline Fuel height & $91 \mathrm{~cm}^{\mathrm{f}}$ & $91 \mathrm{~cm}^{\mathrm{f}}$ & $91 \mathrm{~cm}$ \\
\hline Fuel outer diameter, as-fabricated & $0.56 \mathrm{~cm}^{\mathrm{g}}$ & $0.5 \mathrm{~cm}^{\mathrm{g}}$ & $\mathrm{TBD}^{\mathrm{g}}$ \\
\hline Fuel inner diameter, as-fabricated & $0.15 \mathrm{~cm}^{\mathrm{g}}$ & $\mathrm{n} / \mathrm{a}$ & $\mathrm{n} / \mathrm{a}$ \\
\hline Fuel-cladding bond & $\mathrm{He}$ & $\mathrm{Na}$ & $\mathrm{He}$ \\
\hline Cladding material & $\mathrm{HT} 9^{\mathrm{h}}$ or $20 \%$ cw $316 \mathrm{SS}$ & HT $9^{\mathrm{h}}$ or $20 \%$ cw $316 \mathrm{SS}$ & HT $9^{\text {h }}$ or $20 \%$ cw $316 \mathrm{SS}$ \\
\hline Cladding outer diameter ${ }^{f}$ & $0.69 \mathrm{~cm}$ & $0.69 \mathrm{~cm}$ & $0.94 \mathrm{~cm}$ \\
\hline Cladding inner diameter ${ }^{f}$ & $0.57 \mathrm{~cm}$ & $0.57 \mathrm{~cm}$ & $\mathrm{TBD}^{\mathrm{g}}$ \\
\hline Peak linear heat generation rate & $44-46 \mathrm{~kW} / \mathrm{m}$ & $49-52 \mathrm{~kW} / \mathrm{m}$ & $66-80 \mathrm{~kW} / \mathrm{m}$ \\
\hline Peak inner-wall cladding temperature, nominal & $620^{\circ} \mathrm{C}$ & $620^{\circ} \mathrm{C}^{\mathrm{i}}$ & $620^{\circ} \mathrm{C}$ \\
\hline Duct material & $\mathrm{HT} 9^{\mathrm{h}}$ or $20 \%$ cw $316 \mathrm{SS}$ & HT $9^{\mathrm{h}}$ or $20 \%$ cw $316 \mathrm{SS}$ & $\mathrm{HT} 9^{\mathrm{h}}$ or $20 \%$ cw $316 \mathrm{SS}$ \\
\hline
\end{tabular}

Considered in total, the metal fuel database is substantial, with nearly 30 years of operating experience in EBR-II alone. The evolutionary development leading to $\mathrm{U}-\mathrm{Pu}-\mathrm{Zr}$ has been sufficient to identify and understand the mechanisms that control metal fuel lifetime and safety-related response, and the operating experience in EBR-II has been sufficient to establish the reliability of metal fuel such that fuel utilization of $200 \mathrm{GWd} / \mathrm{MTHM}$ can be expected. $\mathrm{U}-\mathrm{Pu}-\mathrm{Zr}$ fuel technology will benefit from large-scale utilization similar to that of U-Fs and U-Zr fuel in EBR-II and MOX fuel in FFTF, and that will likely be necessary to build confidence prior to an industrial-scale implementation. However, the authors assert that a safety case for use of such fuel in a demonstration or test reactor can be prepared and defended from the existing database, with incorporation of uncertainty factors that can be reduced with further experience. A set of suggested design parameters for use of $\mathrm{U}-\mathrm{Pu}-\mathrm{Zr}$ fuel, derived from experience with fuel irradiated in EBR-II and FFTF, is presented in the table above.

The experience base with mixed nitride fuels and mixed carbide fuels is limited, but carbide fuel technology in the US progressed sufficiently to demonstrate burnup potential of $200 \mathrm{GWd} / \mathrm{MTHM}$ and the absence of any limiting transient-overpower behavior. Mixed carbide fuel technology would benefit from additional development work to evaluate a broader range of irradiation conditions and design parameters. More importantly, future development of MC fuel should address behavior with HT9 (or other low-swelling, ferritic-martensitic alloys) and should seek to establish a sufficient database to establish reliability - such as with a large-scale use of MC fuel for a reactor core. The program and experience in India would necessarily be considered prior to any significant work in the US with carbide fuels. A set of suggested reference design parameters for mixed carbide fuel is presented in the table above, reflecting experience with prior US irradiation testing. In the competitive programs within the US through the 1970s, 1980s, and 1990s each of the R\&D groups advocated the fuel system they worked on, concluding that each fuel system appears capable of meeting SFR fuel requirements. After this retrospective review, the present authors agree MOX, metal, and $\mathrm{MC}$ fuel types all appear capable of 
meeting SFR fuel requirements, with the reliability of MOX and metal fuel already well established. Selection of one fuel system over another will depend on circumstances particular to the application and on issues other than fuel performance, such as fabrication, recycle cost or, overall system safety performance, as has been suggested previously. 


\section{Criticality Experimental Data. The Case of the International Handbook of Evaluated Criticality Safety Benchmark Experiments}

The Criticality Safety Benchmark Evaluation Project (CSBEP) was initiated in October of 1992 by the United States Department of Energy. The project quickly became an international effort as scientists from other interested countries became involved. The International Criticality Safety Benchmark Evaluation Project (ICSBEP) became an official activity of the Organization for Economic Cooperation and Development - Nuclear Energy Agency (OECD-NEA) in 1995.

This handbook contains criticality safety benchmark specifications that have been derived from experiments performed at various nuclear critical facilities around the world. The benchmark specifications are intended for use by criticality safety engineers to validate calculational techniques used to establish minimum subcritical margins for operations with fissile material and to determine criticality alarm requirement and placement. Many of the specifications are also useful for nuclear data testing. Example calculations are presented; however, these calculations do not constitute a validation of the codes or cross section data.

The evaluated criticality safety benchmark data are given in nine volumes. These volumes span over 45,000 pages and contain 485 evaluations with benchmark specifications for 4,207 critical, near critical, or subcritical configurations, 24 criticality alarm placement/shielding configurations with multiple dose points for each, and 155 configurations that have been categorized as fundamental physics measurements that are relevant to criticality safety applications.

Experiments that are found unacceptable for use as criticality safety benchmark experiments are discussed in these evaluations; however, benchmark specifications are not derived for such experiments (in some cases models are provided in an appendix). Approximately 725 experimental configurations are categorized as unacceptable for use as criticality safety benchmark experiments. Additional evaluations are in progress and will be added to this document periodically. The document is organized in a manner that allows easy inclusion of additional evaluations as they become available.

Each experiment has a unique identifier. The elements of the identifier correspond to the categories and subcategories named in the organization section of this report. The identifier takes the following form: (Fissile Material)-(Physical Form)-(Spectrum)-(Three-Digit Numerical Identifier)

Identifier elements and their meanings for each category and subcategory are given below.

\begin{tabular}{|lll|}
\hline Fissile Material & Physical Form & Spectrum \\
\hline & & \\
Plutonium PU & Metal MET & Fast FAST \\
Highly Enriched Uranium HEU & Compound COMP & Intermediate-Energy INTER \\
Intermediate Enriched Uranium IEU & Solution SOL & Thermal THERM \\
Low Enriched Uranium LEU & Miscellaneous MISC & Mixed MIXED \\
Uranium-233 U233 & & \\
Mixed Plutonium - Uranium MIX & & \\
Special Isotope SPEC & & \\
\hline
\end{tabular}

Subcritical measurements are denoted by including the letters "SUB" at the beginning of the identifier. Examples of identifiers are: IEU-COMP-THERM-001 for thermal, intermediate enriched uranium system in which the fissile material is in the form of a compound; HEU-SOL-THERM-001 for highly enriched uranium solution; SUB-HEU-SOL-THERM-001 for subcritical measurements on highly enriched uranium solution systems. 


\section{Reactor Physics Experimental Data. The Case of the International Handbook of Evaluated Reactor Physics Benchmark Experiments}

The International Reactor Physics Evaluation Project (IRPhEP) was initiated as a pilot activity in 1999 by the Organization of Economic Cooperation and Development (OECD) Nuclear Energy Agency (NEA) Nuclear Science Committee (NSC). The project was endorsed as an official activity of the NSC in June of 2003. While coordination and administration of the IRPhEP takes place at an international level, each participating country is responsible for the administration, technical direction, and priorities of the project within their respective countries. The information and data included in this Handbook are available to OECD member countries, to all contributing countries and to others on a case by case basis.

The IRPhEP is patterned after the International Criticality Safety Benchmark Evaluation Project (ICSBEP) and is closely coordinated with the ICSBEP in order to avoid duplication of effort and publication of conflicting information. Some benchmark data are applicable to both nuclear criticality safety and reactor physics technology. Some have already been evaluated and published by the ICSBEP, but have been extended to include other types of measurements besides the critical configuration.

Through this effort, the IRPhEP will be able to (1) consolidate and preserve the information base that already exists worldwide; (2) retrieve lost data; (3) identify areas where more data are needed; (4) draw upon the resources of the international reactor physics community to help fill those needs; (5) identify discrepancies between calculations and experiments due to deficiencies in reported experimental data, cross section data, cross section processing codes, and neutronics codes; (6) eliminate a large amount of tedious and redundant research and processing of reactor physics experiment data; and (7) improve future experimental planning, execution, and reporting.

This Handbook contains reactor physics benchmark specifications that have been derived from experiments that were performed at various nuclear critical facilities around the world. The benchmark specifications are intended for use by reactor designers, safety analysts, and nuclear data evaluators to validate calculational techniques and data. Example calculations are presented; however, these calculations do not constitute validation or endorsement of the codes or cross section data.

This Handbook contains reactor physics benchmark specifications that have been derived from experiments that were performed at various nuclear critical facilities around the world. The benchmark specifications are intended for use by reactor designers, safety analysts, and nuclear data evaluators to validate calculational techniques and data. Example calculations are presented; however, these calculations do not constitute validation or endorsement of the codes or cross section data.

The 2009 Edition of the International Handbook of Evaluated Reactor Physics Experiments contains data from 36 different experimental series that were performed at 21 different reactor facilities. Thirty-three of the 36 evaluations are published as approved benchmarks. The remaining three evaluations are published as DRAFT documents only. Draft documents have been reviewed by the IRPhEP Technical Review Group (TRG); however, all action items could not be completed or reviewed in time for the final publication or, in most cases, the TRG felt it necessary to review the revised evaluations before giving final approval. The Handbook is organized in a manner that allows easy inclusion of additional evaluations, as they become available.

The Handbook is divided into eleven major sections, each representing one of eleven different reactor types. Each experimental series within the Handbook is assigned a unique identifier that consists of two parts. The first part consists of the Reactor Name, Reactor Type, Facility Type, and a Three Digit Numerical Identifier. The second part of the identifier begins on a separate line and includes the Measurement Type(s). Identifiers, therefore, take the following form: (Reactor Name)-(Reactor Type)(Facility Type)-(Three-Digit Numerical Identifier) (Measurement Type(s)) 
Identifier elements and their meanings are given below.

\begin{tabular}{|lll|}
\hline REACTOR TYPE & FACILITY TYPE & MEASUREMENT TYPE \\
\hline & & \\
Pressurized Water Reactor PWR & Experimental Facility EXP & Critical Configuration CRIT \\
VVER Reactor VVER & Power Reactor POWER & Subcritical Configuration SUB \\
Boiling Water Reactor BWR & Research Reactor RESR & Buckling, Extrapolation Length BUCK \\
Liquid Metal Fast Reactor LMFR & & Spectral Characteristics SPEC \\
Gas Cooled (Thermal) Reactor GCR & & Reactivity Effects REAC \\
Gas Cooled FastReactor GCFR & Reactivity Coefficients COEF \\
Light Water Moderated Reactor LWR & Kinetics Measurements KIN \\
Heavy Water Moderated Reactor HWR & Reaction-Rate Distributions RRATE \\
Molten Salt Reactor MSR & & Power Distributions POWDIS \\
RBMK Reactor RBMK & Isotopic Composition ISO \\
Fundamental FUND & & Miscellaneous Measurements MISC \\
\hline
\end{tabular}

NB: The latest version of the Handbook, released in 2009, does not contain data relative to either BWR, or GCFR, or MSR, or RBMK. Furthermore there are no data relative to power reactors. 


\section{The MANTRA Experiment: A New Reactor Physics Experiment in the US}

In this section we describe a new type of experiment that would be characterized as "smart". In fact, it is of the elemental type, thus, the type needed by NEAMS to validate single specific effects, and, moreover, using an approach that allows with very limited means (but taking advantage of new experimental techniques), to achieve results that in the past were obtained using a more classical, but costly, "cook and look" approach.

Advanced nuclear fuel cycles are currently under evaluation in order to assess their potential to cope with new requirements of radioactive waste minimization, optimization of resource utilization and reduced risk of proliferation. This assessment should account for several key features of the fuel cycle, from irradiated fuel processing, innovative fuel development and fabrication, waste characterization and disposal. In some cases, the impact of nuclear data and of their associated uncertainties can be crucial in order to further explore an option, or to reject it. This has been the case for example of the potential spectacular increase of the neutron source at the fabrication of innovative fuels that can be heavily loaded with transuranics (TRUs). The neutron source is due to the build-up during irradiation in successive recycles of high mass transuranic isotopes, in particular $\mathrm{Cm}$ isotopes and $\mathrm{Cf}-252$. The build up of that isotope is the result of radioactive decays and of several successive neutron captures that are particularly effective in thermal neutron spectra. This type of result depends very strongly on the knowledge of higher mass TRU cross sections (capture, fission, $(n, 2 n)$ etc) and on their associated uncertainties.

At present, most evaluated data files provide some information on these isotopes, but up to now, there has been little emphasis on the quality of these data and very little reliable uncertainty estimations have been provided. This situation is due to the difficulty to make both integral and differential cross section measurements for these isotopes.

The objective of this new experiment, called MANTRA, which stands for Measurement of Actinide Neutronic Transmutation Rates with Accelerator mass spectroscopy, is to obtain valuable integral information about actinides neutron cross sections that are of importance for advanced nuclear fuel cycles in a relatively short time compared to the more standard, and more time consuming, route which consists of irradiating samples in a reactor and then performing chemical analysis to characterize the different isotopes produced during irradiation.

The proposed work intends to develop an original approach to take advantage of two experimental facilities: the neutron irradiation capabilities of the Advanced Test Reactor (ATR) at the Idaho National Laboratory and the Accelerator Mass Spectroscopy (AMS) capabilities of the Argonne Tandem Linac Accelerator System (ATLAS) at the Argonne National Laboratory.

The novelty of this experiment relies on the use of AMS which will provide very precise measurements of the different actinides that are built up during the irradiation, up to the highest mass isotopes. Indeed, ATLAS can detect down to about $10^{6}$ atoms which is out of the range of more classical chemical analysis traditionally used to analyze irradiated fuel samples. An important feature of this highly precise isotope discrimination is that the irradiation time does not need to be too long: typically one cycle in ATR (about 50 days) would be sufficient. Another very important and fairly unique feature of the novel approach is that the amount of material to be irradiated and successively analyzed in the AMS facility can be kept extremely low.

In order to reach the objective, the proposed work can be decomposed into three major steps:

1. Preparation and irradiation of some pure actinide samples in ATR. The samples that are available at INL and which are of interest for the advanced fuel cycles are the following: Np237, Pu242, Am241, Am243, Cm244, Cm248. Other Pu and U isotopes will be also irradiated. 
2. Measurements of the mass of the different isotopes in the irradiated samples at ATLAS.

3. Using the results of the measurements to derive information on $(n, g),(n, f)$ and $(n, 2 n)$ cross sections of isotopes in the original sample and produced by the irradiation. An effort will be made also to derive, if possible, fission yields.

The expected outcome of the proposed experiments will be a set of integral experiments providing the measurement of the isotopes built up during the preliminary (short) irradiation in ATR of a series of pure "father" transuranic isotopes. Since several spectrum environments will be experimentally simulated in ATR, the total number of measured nuclear densities $\mathrm{N}$ will be $\mathrm{Ni}, \mathrm{j}, \mathrm{k}$, where $\mathrm{i}=1$...I total number of "father" isotopes; $\mathrm{j}=1$...J number of isotopes measured with AMS for each "father" isotope; $k=1 \ldots \mathrm{K}$ total number of tailored spectra and axial positions in the ATR irradiations.

The "a posteriori" analysis involves evaluation of the transmutation rates via Monte Carlo calculations of the ATR irradiation, so that available data set libraries (e. g. ENDF/B-VII) could be tested against experimental values. Because of the use of a very refined method that allows explicit geometry representation and continuous energy dependence of cross sections, it is expected that, with a large number of neutron histories, the uncertainty associated to the calculation step to be very limited (less than $1 \%)$.

The integral data, together with few already existing and meaningful experiments (sample irradiations in power reactors, selected fission rate measurements in zero power reactors), will be used to validate existing TRU nuclear data and to improve them, via a statistical assimilation process. In order to perform the data assimilation, recently developed covariance data for TRU will be used, together with sensitivity coefficients, based on an adjoint method, accounting, if needed for second order effects. The data assimilation outcome will provide improved TRU nuclear data and new covariance information, provided that the $\mathrm{N}$ nuclear density measurement uncertainties will be kept as low as possible. In fact, in view of the accuracy on atom counting, and limited uncertainties associated to the irradiation step, including calculation approximations, one can target a global uncertainty between 2 to $5 \%$ on the integral cross sections of the measured isotopes.

The data improvements will allow to set up revised nuclear data files to be used for advanced fuel cycle assessments, from fuel fabrication to fuel reprocessing and waste storage, with a high degree of reliability, as required both for economy and safety purposes. 


\section{CONCLUSIONS}

The goal is for all modeling and simulation tools to be demonstrated accurate and reliable through a formal Verification and Validation (V\&V) process, especially where such tools are to be used to establish safety margins and support regulatory compliance, or to design a system in a manner that reduces the role of expensive mockups and prototypes.

Whereas the Verification part of the process does not rely on experiment, the Validation part, on the contrary, necessitates as many relevant and precise experimental data as possible to make sure the models reproduce reality as closely as possible.

Hence, this report presents a limited collection of experimental data that could be used to validate the codes mainly devoted to Fast Neutron Reactor calculations in the US. Emphasis has been put on existing data for thermal-hydraulics, fuel and reactor physics. The principles of a new experiment that could be used to ameliorate our knowledge of neutron cross-sections are presented as well. In short, it consists in irradiating a few milligrams of actinides and analyzing the results with Accelerator Mass Spectroscopy to infer the neutron cross-sections.

A methodology that has been used essentially in neutronics to adjust neutron cross-sections is presented as well. Since it relies, in essence, only on sensitivity coefficients and covariance matrices, it is very general and could in principle be applied to other fields as long as the physics does not exhibit too strong non-linearities. However, even in the case of large nonlinearity the same approach can be used in an iterative way, where successive linear applications are used until convergence.

Finally, the wealth of experimental data relevant to Fast Neutron Reactors in the US should not be taken for granted and efforts should be put on saving these 30-40 years old data and on making sure they are validation-worthy, i.e. that the experimental conditions and uncertainties are well documented. 